\title{
The Frequency of Morpho-Syntactic Errors by Kurdish EFL Learners
}

\author{
Aras Abdalkarim Amin \\ Department of English/Cihan University/Sulaimani
}

\begin{abstract}
The current paper is entirely concerned with analyzing the possible errors that the Kurdish learners commit while attempting at translating specific Kurdish sentences into English. The paper mainly focuses on analyzing the morphological and syntactical errors including the use of articles, prepositions and other related aspects of morphology. It combines both morphology and syntax so as to shed lights on the weakness and awkward performance of language in this respect. The study reveals that the learners do commit various errors at the morphological and syntactic levels of language. It shows that there are specific attributes which lead to the occurrences of such kinds of errors.
\end{abstract}

Keywords:- Error analysis, Interlingual errors, Intralingual errors, EFL learners.

\section{INTRODUCTION}

The study of error analysis is one of the most influential areas in the learning and understanding of the mechanisms of language. In other words, it shows how language functions at the various levels by analyzing the frequent committed mistakes. Such analysis will definitely lead to a better estimation of language performance. As a result of the new research interest the processes and strategies of the first and second-language acquisition, the study of errors, both those made by the native child and the second language learners, became crucially important. That is why errors were seen as evidence of the processes and strategies of language acquisition. Menyuk (1971) claims that the study of the child native language learner's errors throws light on the types of cognitive and linguistic processes that appear to be part of the language learning process. It is widely believed that language learning, like acquiring virtually any other human learning, involves the making of errors. As Dulay, Burt \&Krashen (1982) assert, people cannot learn language without first systematically committing errors. The learner profits from his/her first errors by using them to obtain feedback from the environment and in turn use that feedback to test and modify his/her hypothesis about the target language. That is why, from the study of learner's errors we are able to get some information about the nature of his/her knowledge of the target language at a given point in his/her learning career and discover what s/he still has to learn. Behaviorist accounts claim that transfer is the cause of errors, whereas from a cognitive perspective, transfer is seen as a resource that the learner actively draws upon in interlanguage development (Selinker, 1972).

Based on Keshavarz (2014, p.59) it can be concluded that error analysis is based on three important assumptions as follows:

1. Errors are inevitable as we cannot learn a language without committing errors.

2. Errors are significant in different ways.

3. Not all errors are attributable to the learner's mother tongue, i.e. first language interference is not the only source of errors.

Some findings show that the process of learning the second language is nearly the same as the native language. Making lots of mistakes by a child who wants to learn his or her native language is considered a natural process of language acquisition. Adults help them by giving feedbacks and by this way they will gradually produce grammatically and semantically correct sentences. Errors are unavoidable in learning a foreign language. Teachers should first recognize the errors made by the students and block some of these errors by giving feedbacks to them.

\section{LITERATURE REVIEW}

Systematically analyzing errors made by language learners makes it possible to determine areas that need reinforcement in teaching (Corder, 1975). Error analysis emphasizes "the significance of errors in learners' interlanguage system" (Brown, 1994, p. 204). The term interlanguage, introduced by Selinker(1972), refers to the systematic knowledge of an L2 which is independent of both the learner's L1 and the target language. Nemser (1971) referred to it as the "Approximative System" and Corder (1967) as the "Idiosyncratic Dialect". In fact, the significance of errors is emphasized by many scholars in the field of error analysis who have stressed 
such significance while studying the performance of second language acquisition and learning. The 'father' of Error Analysis 'Corder' was initiated a new turn in the study of error analysis. He contended that errors are important in and of themselves. He, in his influential article (1967), remarks that errors are significant in three different ways. First to the teacher, in that they tell him, if he undertakes a systematic analysis, how far towards the goal the learner has progressed and, consequently, what remains for him to learn. Second, they provide to the researcher evidence of how language is learnt or acquired, and what strategies or procedures the learner is employing in his discovery of the language. In fact, the researchers are interested in errors because they are believed to contain valuable information on the strategies that people use to acquire a language. Thirdly, they are indispensable to the learner himself, because the making of errors is a device the learner uses in order to learn. In other words, it is a way through which the learner tests his hypotheses about the nature of the language s/he is learning (Corder, 1967). Gass and Selinker (2008) dealt with errors as "red flags" which provide evidence of the learner's knowledge of the second language. Error analysis has made a significant contribution to the theoretical consciousness-raising of applied linguists and language practitioners. Sridhar (1981, pp. 221-2) lists the goal of applied error analysis as follows:

- Determining the sequence of the presentation of target language items in textbooks and classrooms, with the difficult items following the easier ones.

- Deciding the relative degree of emphasis explanation, and practice required in putting across various items in the target language.

- Devising remedial lessons and exercises.

- Selecting items for testing the learner's proficiency.

Ellis (2008, p. 961) adds that "error analysis involves a set of procedures for identifying, describing and explaining errors in learner language."

\section{METHODOLOGY}

In this section a detailed description of the used methodology is discussed including the participants, the materials, population of the study and other related items. The significance of methodology is that it verifies the entire hypotheses of the paper and this is done through identifying the various errors and then transcribes them efficiently so as to have entirely objective results.

\section{Participants}

Participants in this study were $20 \mathrm{EFL}$ students selected from Cihan University/ Sulaimani/Department of English/ second year students.

\section{Instrument/Materials}

The instrument consists of 14 written Kurdish sentences, and the participants were asked to write the equivalent in English in 30 minutes.

\section{Data Collection procedure}

The written permission from the head of the department was taken before conducting this research. After introducing the task, students were asked to write the proper equivalent in English for each Kurdish item. They had to translate the items in 30 minutes.

\section{RESULTS AND DISCUSSIONS}

The first step, after the papers had been written, and the samples collected, was reading the sentences carefully. The errors were identified. Then, they were categorized according to their linguistic specifications and linguistic taxonomy of errors which we can apply to corpus. This linguistic taxonomy classified errors according to errors which had been committed in linguistic items. Then, these categories were classified into sub-categories in order to give more detailed explanation. In this study, the linguistic taxonomy of errors prepared by (Keshavarz, 2014) was applied. The first step, after the papers had been written, the samples were collected, and identifying and categorizing the errors, the frequency and percentage of errors were counted, in order to know which categories were committed most frequently by the students. The percentage of each category was calculated by using the following formula:

Frequency of errors in each category

Total number of errors

$\times 100 \%$

After the calculation was done, the highest percentage of a particular category was revealed. The following table illustrates all the percentages of the committed errors by learners as far as morphology and syntax are concerned. 
Table 1: Frequency of Morpho-syntactical errors.

\begin{tabular}{|l|c|c|}
\hline Morpho-syntactical errors & Number of errors & \% \\
\hline Wrong use of preposition & 41 & $20.81 \%$ \\
\hline Errors in the use of articles & 29 & $14.72 \%$ \\
\hline Typical Kurdish construction & 25 & $12.69 \%$ \\
\hline Errors in the use of prepositions & 35 & $17.76 \%$ \\
\hline Subject-verb inversion in indirect questions & 9 & $4.56 \%$ \\
\hline Wrong use of tense & 42 & $21.31 \%$ \\
\hline Wrong use of adjective & 7 & $3.55 \%$ \\
\hline Wrong use of negative construction & 3 & $1.52 \%$ \\
\hline Replacement of incorrect element for correct ones & 6 & $3.04 \%$ \\
\hline & 197 & \\
\hline
\end{tabular}

The table shows in detail the main errors which are committed by the Kurdish EFL learners. The majority of the errors can be because of L1 transfer. The influence of the L1 on the target language is a reason that learners always encounter in their real-life in language-related problem. The results of this study also show that most errors that commit by learners due to the lack of information about the target language or may be sometimes the errors committed by the learners as a result of intralingual and developmental errors are caused by the mutual interference of items in the target language, i.e., the influence of one target language item upon another. Most of the learners know the rules but they do not have enough practice that is why they use one rule to all, which is called overgeneralization. The findings also confirm that most of the errors made by learners were not under the influence of their native language. Teachers should be aware of the distinction between errors and mistakes; they should be treated separately. Errors are rule governed and systematic in nature and such indicative of the learners' linguistic system at a given stage of language learning. In contrast to errors, mistakes are random deviations and unrelated to any system, such as slips of tongue or pen, false starts and the like.

\section{CONCLUSION}

In the process of language learning learners are always made errors as a natural step in the development of language skills. Many language educators today propose that foreign language teachers should expect different types of errors from their students; these errors which are commit by the learners, teachers should accept those errors as a natural phenomenon integral to the process of learning second language. Foreign language learners tend to commit relatively more errors in spontaneous speech than in written discourse. There tend to be various degrees of monitoring, and its degree of accuracy, depending on the task language learners perform and the amount of attention they pay to form. Even native speakers exhibit differences in performance between writing and spontaneous speech. We have to remember that teachers are part of the errors; teacherinduced errors are those which results from pedagogical procedures contained in a text or employ by the teacher. An induced error is an error, which has been presented or practiced though teaching techniques or course design. A teacher may unintentionally mislead his students by the way he defines a lexical item, or by the order in which he presents teaching material.

\section{REFERENCES}

[1] Brown, H. D. (1994). Teaching by principles: interactive language teaching methodology. New York: Prentice Hall Regents.

[2] Corder, S. P. (1967).The Significance of Learner's Errors. IRAL, 5 (4), 147-170.

[3] Corder, S. P. (1975). Error analysis, interlanguage and second language acquisition. Language Teaching, 8(4), 201 218.

[4] Dulay, H. C., Burt,M. K., \& Krashen, S.D. (1982). Language Two. Oxford: Oxford University Press.Ellis, R. (2008). The study of Second Language Acquisition. Oxford: Oxford University Press.

[5] Gass, S. M., \&Selinker, L. (2008). Second language acquisition: An introductory course. New York: Routledge.

[6] Johanson, S. (1975). The uses of error analysis and contrastive analysis. English Language Teaching, Vol. 29, No.3, pp.246-253.

[7] Keshavarz, M. H. (2014). Contrastive analysis and error analysis. Tehran: Rahnamah.Menyuk, P. H. (1971). The acquisition and development of language. Engleewood Cliffs, New Jersey: Prentice-Hall Inc.

[8] Menyuk, P. H. (1971). The acquisition and development of language. Engleewood Cliffs, New Jersey: Prentice-Hall.

[9] Nemser, W. (1971).Approximative Systems of Foreign Language Learners.IRAL,9(2), 115-124.Selinker, L. (1972). Rediscovering interlanguage.New York: Longman.

[10] Selinker, L. (1972). Rediscovering interlanguage. New York: Longman.

[11] Sridhar, S. N. (1981). Contrastive analysis, error analysis, and interlanguage: three phases of one goal. In J. Fisiak, (ed), Contrastive linguistics and the language teacher (pp. 207-241). Oxford: Pergamon Press. 